\title{
Erratum to: Generation of Lithium Clusters in Helium Plasma Flow
}

\author{
A. V. Popov ${ }^{a, *}$ and V. A. Popov ${ }^{a}$ \\ ${ }^{a}$ Polzunov Altai State Technical University, Barnaul, 656038 Russia \\ *e-mail:Popov.Barnaul@mail.ru \\ Received August 14, 2019
}

DOI: $10.1134 / \mathrm{S} 106378421909024 \mathrm{X}$

In REFERENCES, entries 30, 31, 33, 34, 36, and 38 should be read as

30. A. V. Popov, Opt. Spectrosc. 93, 1 (2002). https://www.doi.org/10.1134/1.1496715

31. A. V. Popov, J. Exp. Theor. Phys. 101, 197 (2005). https://www.doi.org/10.1134/1.2047785

33. A. V. Popov, Tech. Phys. 55, 188 (2010). https://www.doi.org/10.1134/S1063784210020040
34. A. V. Popov, Crystallogr. Rep. 61, 1 (2016). https://www.doi.org/10.1134/S106377451601017X

36. A. V. Popov, Phys. Solid State 50, 795 (2008). https://www.doi.org/10.1134/S106378340804032X

38. A. V. Popov, Phys. Solid State 50, 1592 (2008).https://www.doi.org/10.1134/S106378340808 0349

The original article can be found online at https://doi.org/10.1134/S1063784219080176 